\title{
Experimental Research on the Monosyllabic Tones of Wudu Dialect
}

\author{
Hongjie Wang1, a, Yonghong Li1, b* \\ ${ }^{1}$ Key Lab of China's National Linguistic Information Technology, Northwest Minzu University, Lanzhou, 730030 China \\ a1778157404@qq.com, blyhweiwei@126.com
}

\begin{abstract}
This paper uses the method of experimental phonetics analysis the tones of Wudu dialect. Through recording, extracting and analysis data, we get a conclusion that there are three tones in Wudu dialect, they are Yinping (41), Yangping (13) and Shang (44). We found that Ru was all merged into Yangping. This article makes an objective description of the specific situation of the Wudu dialect and to provide some reference for the study of Wudu dialect in the future.
\end{abstract}

Keywords-Tianshui dialect; Monosyllabic tones; Experimental phonetics

\section{INTRODUCTION}

Wudu is located in the southeast of Gansu Province. It is located in the Qinba Mountain Area and at the junction of Gansu, Shaanxi and Sichuan provinces. It is the political, cultural and economic center of the Longnan City. The dialect in Gansu province can be divided into three parts: Zhongyuan Mandarin, Lanyin Mandarin and Southwest Mandarin. The largest number of people used in the Zhongyuan Mandarin. Its basic features are "voiceless, asperational voiceless and secondary voiced of $\mathrm{Ru}$ was merged into Yinping now. The voiced of $\mathrm{Ru}$ was merged into Yangping". Zhongyuan Mandarin can be divided into three parts: Longzhong film, Qinlong film and Guanzhong film. Wudu dialect belongs to Qinlong film. So far, linguists have done a small amount of research on Wudu dialect. In A study of the Southwest Mandarin in Gansu, Mochao studied on the sound system of Fengxiang in Wudu County. He point out that there are four tones in Fengxiang dialect and they are Yinping (334), Yangping (31), Shang (53) and Qu (24). ${ }^{1}$ This article will study the tones of Wudu dialect from the perspective of experimental phonetics and quantitative analysis them. Finally it will provides a reference for the further study of Wudu dialect [1].

\section{EXPERIMENTAL DESCRIPTION}

Pronunciation table. The main task of this experiment is to have a comprehensive depiction and analysis to Wudu dialect using the method of experimental phonetics. In this paper, we according to Dialect Survey Questionnaire to determine the experimental pronunciation list (Table 1). The design of the word list follows the principles below: 1) In each words, the boundaries of consonants and vowels should be obvious. 2) About each words, the final of a syllable should be a pure vowel, reduce tongue movement and avoid affecting the accuracy of data. 3) Consider the minimal pair in each tones.

TABLE I. PRONUNCIATION LIST

\begin{tabular}{|c|c|c|}
\hline Ancient tone & Ancient sound & Cases of words \\
\hline \multirow{4}{*}{ Ping } & Voiceless & 东、该、灯、风 \\
\cline { 2 - 3 } & Asperational voiceless & 通、开、天、春 \\
\cline { 2 - 3 } & Secondary voiced & 门、龙、牛、油 \\
\cline { 2 - 3 } & Voiced & 铜、皮、糖、红 \\
\hline \multirow{5}{*}{ Shang } & Voiceless & 懂、古、鬼、九 \\
\cline { 2 - 3 } & Asperational voiceless & 统、苦、讨、草 \\
\cline { 2 - 3 } & Secondary voiced & 买、老、五、有 \\
\cline { 2 - 3 } & Voiced & 动、罪、近、后 \\
\hline \multirow{5}{*}{ Qu } & Voiceless & 冻、怪、半、四 \\
\cline { 2 - 3 } & Asperational voiceless & 痛、快、寸、去 \\
\cline { 2 - 3 } & Secondary voiced & 卖、路、硬、乱 \\
\cline { 2 - 3 } & Voiced & 洞、地、饭、树 \\
\hline \multirow{5}{*}{ Ru } & Voiceless & 谷、百、搭、节、急 \\
\hline & Asperational voiceless & 哭、拍、塔、切、刻 \\
\cline { 2 - 3 } & Secondary voiced & 六、麦、叶、月 \\
\cline { 2 - 3 } & Voiced & 毒、白、盒、罚 \\
\hline
\end{tabular}

The speaker is Wudu natives, rarely go out and his dialects are not affected by Mandarin. In order to pronounce naturally, we ask the speaker to be familiar with the table and to practice it before recording [2].

Recording Adobe Audition 3.0, a computer, a microphone are used when recording. When recording, the sampling frequency is $22050 \mathrm{~Hz}$, mono recording and the sampling accuracy is 16 bits.

Speech analysis (1) Voice segmentation and labeling. Record with Audition 3.0 and save them as wav format. Segment and label qualified samples. (2) Extract the fundamental frequency data. Extract the base frequency of each eligible audio and place it in the table. (3) Processing all fundamental frequency data and all values are normalized. The fundamental frequency is normalized by Shi Feng's proposed T-value fundamental frequency normalization formula:

$$
\mathrm{T}=[(\operatorname{lgF} 0-\operatorname{lgmin}) /(\operatorname{lgmax}-\operatorname{lgmin})] * 5
$$


F0 is the average fundamental frequency of the observation point, min and $\max$ are the minimum and maximum fundamental frequency value, $\mathrm{T}$ is the normal result. The value of the $\mathrm{T}$ calculated in this way is in the range of $0-5$. According to the correspondence in Table 2 to determine the five degrees.

TABLE II. THE CORRESPONDING OF FIVE DEGREE VALUE AND T VALUE

\begin{tabular}{|c|c|c|c|c|c|}
\hline T value & $0-1$ & $1-2$ & $2-3$ & $3-4$ & $4-5$ \\
\hline $\begin{array}{c}\text { Five } \\
\text { degrees }\end{array}$ & 1 & 2 & 3 & 4 & 5 \\
\hline
\end{tabular}

\section{DATA ANALYSIS}

After extracting the fundamental frequency data of all the samples and normalizing them, calculate the average of voiceless, asperational voiceless, secondary voiced and voiced of each tone. Figure 1, figure 2, figure 3 and figure 4 are fundamental frequency curves for Ping, Shang, $\mathrm{Qu}$ and $\mathrm{Ru}$. Finally get their domain value [3].

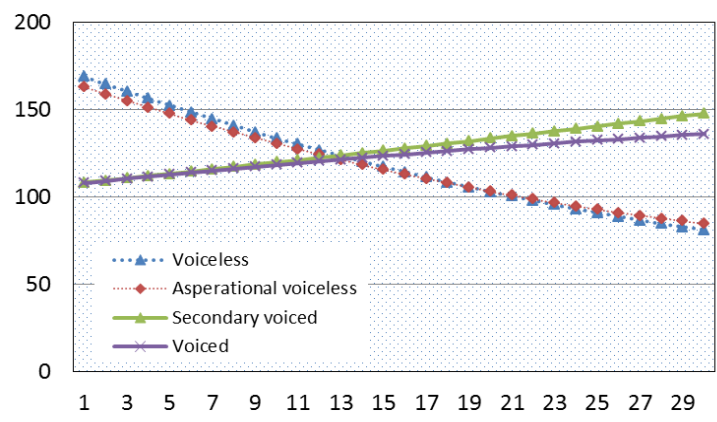

Fig. 1. Fundamental frequency curve of Ping

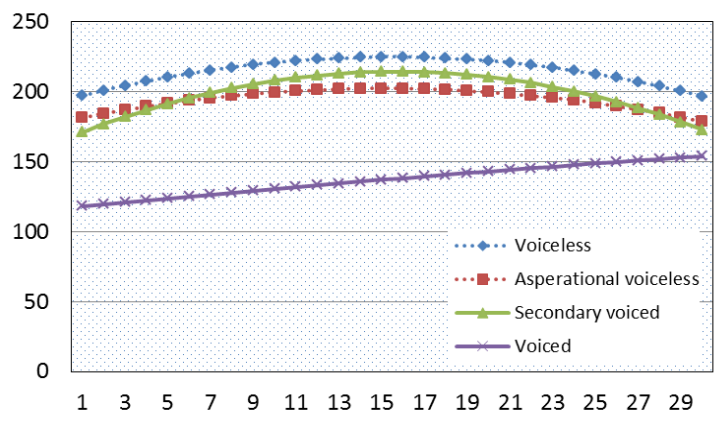

Fig. 2. Fundamental frequency curve of Shang

Ping In ancient phonology, Ping was divided into Yinping and Yangping in most dialects. Figure1 is the fundamental frequency curve for Ping. In Wudu dialect, Ping was divided into Yinping and Yangping. Voiceless and asperational voiceless are falling tones, the maximum and minimum fundamental frequency are $185.2 \mathrm{~Hz}$ and $77.2 \mathrm{~Hz}$ and the domain value is $108 \mathrm{~Hz}$. The secondary voiced and voiced are rising tones. The maximum and minimum fundamental frequency are $154.7 \mathrm{~Hz}$ and $93.7 \mathrm{~Hz}$, its domain value is $61 \mathrm{~Hz}$.

Shang Figure 2 is the fundamental frequency curve for Shang. In Wudu dialect, Shang was divided into two tones.
Voiceless, asperational voiceless and secondary voiced are level tones, and the maximum fundamental frequency is $220.3 \mathrm{~Hz}$ and the minimum is $186.8 \mathrm{~Hz}$, its domain value is $44 \mathrm{~Hz}$. The voiced of Shang is a rising tone, its maximum and minimum fundamental frequency are $170 \mathrm{~Hz}$ and $105.9 \mathrm{~Hz}$, the domain value is $64.1 \mathrm{~Hz}$.

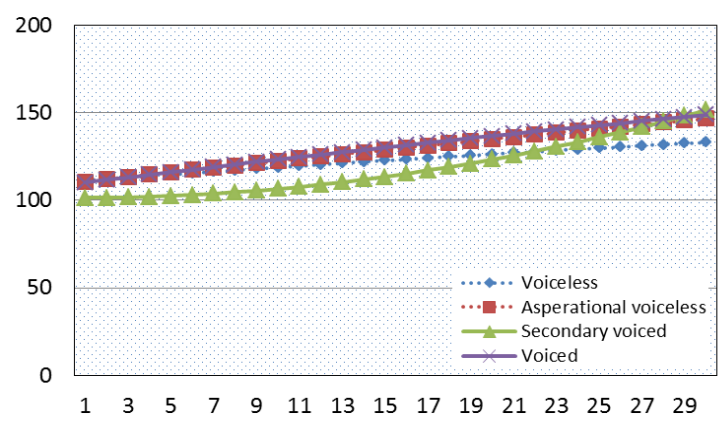

Fig. 3. Fundamental frequency curve of Qu

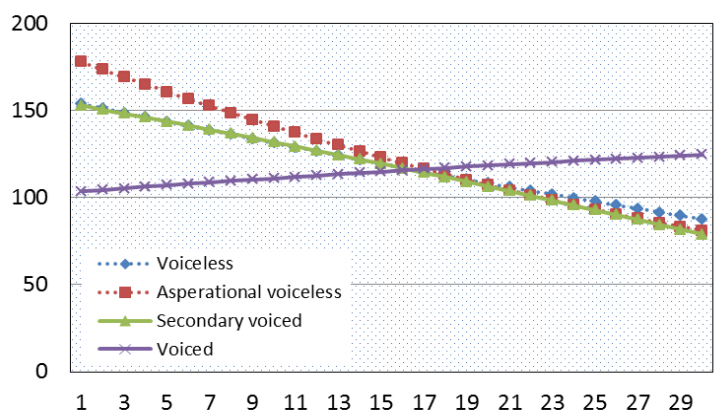

Fig. 4. Fundamental frequency curve of Ru

Qu Figure 3 is the basic frequency curve for $\mathrm{Qu}$ and in Wudu dialect it is a rising tone. The maximum and minimum fundamental frequency are $151.7 \mathrm{~Hz}$ and $101.4 \mathrm{~Hz}$ and the domain value is $50.3 \mathrm{~Hz}$. So, its domain value is close to Yangping.

$\mathrm{Ru}$ Figure 4 is the basic frequency curve for $\mathrm{Ru}$. In Wudu dialect, $\mathrm{Ru}$ was divided into two tones.

Voiceless, asperational voiceless and secondary voiced are falling tones. The maximum and minimum fundamental frequency are $178 \mathrm{~Hz}$ and $78.9 \mathrm{~Hz}$, the domain value is $99.1 \mathrm{~Hz}$. It is close to Yinping. The voiced of $\mathrm{Ru}$ is a rising tone. The maximum and minimum fundamental frequency are $136.8 \mathrm{~Hz}$ and $89.4 \mathrm{~Hz}$, the domain value is $47.4 \mathrm{~Hz}$ [4].

\section{FIVE DEGREES CALCULATION}

Through the analysis of Wudu dialect fundamental frequency, we found that in ancient there are four tones in Wudu dialect, but now there are a lot of changes. Ping was divided into Yinping and Yangping [5], Yinping is a falling tone and Yangping is a rising tone. Voiceless, asperational voiceless and secondary voiced of Shang are changed into a level tone, the voiced of Shang is changed into a rising tone. There was no differentiation of $\mathrm{Qu}$ and it is a rising tone. $\mathrm{Ru}$ was divided into two tones. Voiceless, asperational voiceless 
and secondary voiced of $\mathrm{Ru}$ are falling tone and the voiced of $\mathrm{Ru}$ is a rising tone [6].

According to Mr. Shi Feng's $\mathrm{T}$ value method, the fundamental values of 30 points of each word extracted from this experiment are substituted into F0 respectively. Then put the calculated data into the Excel and draw the $\mathrm{T}$ value curves for three tones in Wudu dialect. We concludes that there are three tones in Wudu dialect, they are Yinping (41), Yangping (13) and Shang (44). The voiced of Shang, Qu and the voiced of $\mathrm{Ru}$ all merged into Yangping. Voiceless, asperational voiceless and secondary voiced of Ru merged into Yinping.

TABLE III. The Monosyllabic TONES OF Wudu Dialect

\begin{tabular}{|c|c|c|c|}
\hline Ancient tones & Ancient sound & Tones & Five degrees \\
\hline \multirow{4}{*}{ Ping } & Voiceless & \multirow{2}{*}{ Yinping } & \multirow{2}{*}{41} \\
\hline & Asperational voiceless & & \\
\hline & Secondary voiced & \multirow{2}{*}{ Yangping } & \multirow{2}{*}{13} \\
\hline & Voiced & & \\
\hline \multirow{4}{*}{ Shang } & Voiceless & \multirow{3}{*}{ Shang } & \multirow{3}{*}{44} \\
\hline & Asperational voiceless & & \\
\hline & Secondary voiced & & \\
\hline & Voiced & \multirow{5}{*}{ Yangping } & \multirow{5}{*}{13} \\
\hline \multirow{4}{*}{$\mathrm{Qu}$} & Voiceless & & \\
\hline & Asperational voiceless & & \\
\hline & Secondary voiced & & \\
\hline & Voiced & & \\
\hline \multirow{4}{*}{$\mathrm{Ru}$} & Voiceless & \multirow{3}{*}{ Yinping } & \multirow{3}{*}{41} \\
\hline & Asperational voiceless & & \\
\hline & Secondary voiced & & \\
\hline & Voiced & Yangping & 13 \\
\hline
\end{tabular}

\section{SUMMARY}

Through the acoustic analysis of Wudu dialect tones and the statistics and calculation of experimental data, this paper draws the following conclusions: (1) In Wudu dialect, there are three tones. (2) Yinping is a falling tone and the value is 41. (3) Yangping is a rising tone and the value is 13. (4) Shang is a level tone and the value is 44 .

\section{ACKNOWLEDGEMENT}

This work was financially supported by the Central University Innovation Project Multi-mode Phonetic Research (31920160002).

\section{REFERENCES}

[1] Wu Zongji, Lin Maocan, Experimental phonetics overview, Beijing, Higher Education Press, 1989.

[2] Luo Changpei, Wang Jun, Essentials of general phonetics, Beijing, Science Press, 1957.

[3] Mo super, Yin Wen. Research on the Southwest Mandarin in Gansu, [J] language science, 2013,12 (06): 658-668.

[4] Luo Peng. The present studies of Gansu dialect and the partition [J]. Journal of Gansu normal colleges, 2007, (04): 1-4.

[5] Liu Xiangqin. Discussion on Qinzhou dialect phonology and the characteristics of modern Chinese language ([J]. language version of the research, 2012), (06): 14-15.

[6] Che Rui. Experimental study on tones of Yongdeng dialect in Gansu

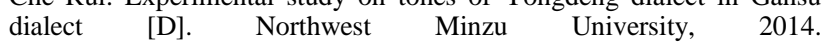

